\title{
Membrane lipid modification and immune function
}

By A. D. Smith, D. M. Conroy and J. Belin, Department of Chemical Pathology and Courtauld Institute of Biochemistry, The Middlesex Hospital Medical School, Mortimer Street, London $W_{\mathrm{I}} P{ }_{7} P N$ and C. D. STuBbs, Department of Pathology, Hahnemann University, Broad and Vine, Philadelphia, PA 19102, USA

Variation in the dietary intake of specific nutrients is known to influence the immune response, but only relatively recently has much attention been paid to the role of dietary fat. In 1976 Mertin \& Hunt reported that essential fatty acid deficiency could significantly accelerate the rejection of skin allografts in mice, a response closely associated with cell-mediated immunity. In the same year it was reported that susceptibility to infection with coxsackie virus B was enhanced in hypercholesterolaemic mice (Loria et al. 1976) and, later, that normal plasma lipoproteins could inhibit lymphocyte proliferation in response to lectins or allogeneic cells (Morse et al. 1977). At about this time also, there was renewed interest in the mechanisms underlying the association between certain forms of cancer and dietary fat, which had emerged both from epidemiological and animal studies (Carroll \& Khor, 1975). A number of reports indicated that the increased tumorigenesis associated with high levels of dietary fat could result from a modified immune response (Broitman et al. 1977; Santiago-Delpin \& Szepsenwol, 1977; Kollmorgen et al. 1979). Since then, a considerable interest has arisen in the effect of lipids on the immune response. However, there has been some disagreement between laboratories on a number of points as described in the present review, and it is therefore necessary to emphasize at the outset that interpretation of the different results discussed requires precision in defining experimental indices. For example, it is necessary to segregate results obtained from experiments in which fatty acids are administered by subcutaneous injection from those derived from dietary treatment. It is even apparent that administration of acids by mouth may not be equivalent in effect to dietary supplementation (Sanders et al. 1985 ). Moreover, if a fat-free diet is compared with a diet rich in polyunsaturated fatty acids it is unclear whether it is the difference in quantity or the quality of the fat that is responsible for any difference between treated groups. It is equally important to define the assay used. Both delayed-type hypersensitivity responses and tests for cytotoxicity represent phenomena associated with the cell-mediated immune response, but the point at which the mechanisms are affected by dietary lipid may differ. Even in evaluating a single type of response, the experimental conditions of two different types of assay may be such that the lipid may influence the outcome differently in the two different assays. 


\section{Outline of immune regulatory mechanisms}

The complexity of immune regulatory mechanisms provides many points at which lipids may interact with immune function. Fig. 1. summarizes one recently-suggested scheme of interactions between cells during antigen stimulation. Feeding diets rich in polyunsaturated fatty acids can modify the fatty acid composition of the membranes of immunocompetent cells (Tsang et al. 1980; Marshall \& Johnston, 1983 ). This may affect the activity of receptors; fatty acids of different degrees of saturation have been shown to modify rosetting of sheep erythrocytes to human lymphocytes (Papamichail et al. 1979). Alternatively, the response to receptor activation may be altered; unsaturated fatty acids inhibit lymphocyte capping (Mandel \& Clark, 1978; Santiago-Delpin et al. 1982) and in in vitro systems lymphocyte transformation is inhibited (Mertin, 1982) although, as

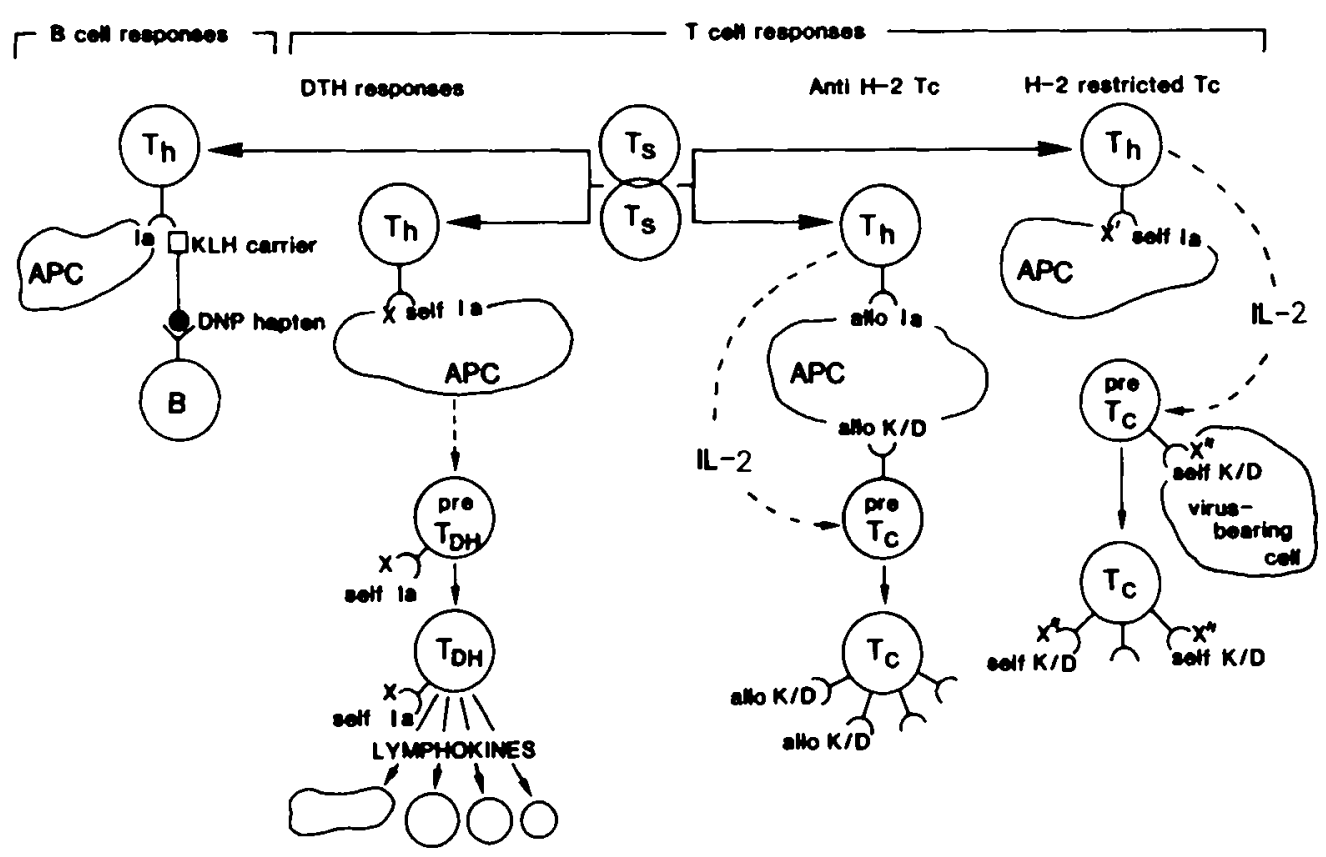

Fig. 1. Cellular interactions in the immune response. The immune response embraces B-cell reactions leading to the secretion of soluble antibody or $T$-cell reactions concerned with cell-mediated immunity. T-cell reactions can be further subdivided into delayed-type hypersensitivity reactions or cytotoxicity reactions which may be restricted by antigens of the major histocompatibility complex (MHC). In the mouse, these derive from the H-2 system and responses are then termed $\mathrm{H}-2$ restricted. Alternatively, immune responses may be directed against alloantigens of the MHC and, in the mouse, can then be termed anti-H-2 reactions.

The T cells comprise subsets of helper cells $\left(\mathrm{T}_{h}\right)$, suppressor cells $\left(\mathrm{T}_{\vartheta}\right)$, precursors of effector $\mathrm{T}$ cells (pre- $T_{\partial}$ ) or effector $T$ cells $\left(T_{\partial}\right)$. For the initiation of an immune response, antigen $\left(X, X^{\prime}\right.$ or $\left.X^{\prime \prime}\right)$ is presented to helper cells by an antigen-presenting cell (APC), which may be a macrophage, dendritic cell or other cell type (Fontana $e t$ al. 1984 ). These antigens are presented by macrophages or other cells carrying MHC gene products (e.g. self Ia, allo Ia, self $\mathrm{K} / \mathrm{D}$ ). Delayed-type hypersensitivity mediating $\mathrm{T}$ cells $\left(\mathrm{T}_{\mathrm{DH}}\right)$ are produced by related mechanisms. (Adapted from Simpson \& Chandler, 1981). 


\section{Vol. 44 Nutritional aspects of membrane structure and function}

discussed later, care is needed because of the possibility of artefacts arising from the toxic action of the free fatty acids in the interpretation of the results of such in vitro experiments (see Stubbs \& Smith, 1984).

\section{Modulation by cholesterol}

The effects of cholesterol on lymphocyte function have recently been summarized (Traill \& Wick, 1984). Feeding diets rich in saturated fatty acids is known to elevate plasma cholesterol levels and thereby can alter the cholesterol:phospholipid value of blood cells, leading to altered function of the lymphocyte. Therefore, in considering the effect of modifying dietary lipid with respect to fatty acyl group unsaturation, possible effects mediated through changes in cholesterol level have to be borne in mind. A correlation between high-density-lipoprotein cholesterol and the number of spleen antibody-forming cells in rats immunized with sheep erythrocytes was observed by Carlomagna et al. (1983).

\section{Effects of plasma lipoproteins}

It is known that the plasma lipoprotein fraction contains components which affect the behaviour of lymphocytes in culture. The most inhibitory fraction is the low-density-lipoprotein fraction (evidence recently summarized by Cuthbert \& Lipsky (r983). The way in which diet affects this inhibitory action of the plasma lipoproteins has not been extensively studied but, as discussed later, several groups have observed that modulation of mitogen stimulation of spleen cells is partially mediated through plasma factors (Kollmorgen et al. 1979; Friend et al. 1980).

\section{Dietary modifications leading to altered immune function}

As mentioned previously, Mertin \& Hunt (1976) found that essential fatty acid (EFA) deficiency stimulated allograft rejection in mice. They also demonstrated in the same study that injected polyunsaturated fatty acids would prolong the life of allografts of $\mathrm{C}_{3} \mathrm{H}$ tail skin on to $\mathrm{CBA}$ mice and later (Mertin et al. 1977) the immune response was implicated in this action by the demonstration that removal of the spleen abrogated the effect. It had been known for some time before this (DiLuzio, 1972) that injection of lipids can stimulate the reticuloendothelial system, and splenomegaly with accumulation of granulocytes was one of the observations made by Mertin and his collaborators (Mertin et al. 1977) in their experiments, together with enhanced carbon uptake, indicative of increased reticulo-endothelial function. Mertin (1976) also showed that primary and subsequent memory cytotoxic responses of spleen cells were decreased in the animals injected with linoleic acid. Subcutaneous injection of polyunsaturated fatty acids is not directly comparable with dietary enrichment with polyunsaturated oils, so that confirmation that similar effects could be obtained by dietary modification was needed. The effect of dietary modification has now been the subject of a number of reports. 
The response of spleen cells to mitogens (Con A, PHA) is depressed by the feeding of polyunsaturated fat (Kollmorgen et al. 1979; Friend et al. 1980; Locniskar et al. 1983). Kollmorgen et al. (1979), using rats, and Friend et al. (1980), using guinea-pigs, found that the serum of animals fed on polyunsaturated fats contained a highly inhibitory component. However, both Kollmorgen et al. (1979) and Locniskar et al. (1983) found that rat spleen lymphocytes taken from animals fed on polyunsaturated fats exhibited a depressed mitogen (Con A) response even when cultured in a serum (horse or fetal bovine) indifferent with regard to dietary fat. A high dietary level of maize oil $(300 \mathrm{~g} / \mathrm{kg})$ has been compared with a low level $(50 \mathrm{~g} / \mathrm{kg})$ and found to give a depressed response to PHA (Nutter et al. I982). On the other hand, a recent study using purified triglycerides as the source of dietary fat failed to reveal a difference between saturated and polyunsaturated fat (Clifford et al. 1983). There is nevertheless, evidence from a number of studies that the feeding of polyunsaturated fat does depress the response of spleen cells to mitogens. In one study it was found that the effect of diets given during the weaning period persisted for up to I I months of age (Carlomagna et al. I983). Delayed-type hypersensitivity responses have been found to be reduced (Friend et al. 1980) or not affected (DeWille et al. 1981) by the feeding of polyunsaturated fat. However, the conditions used (high saturated fat $v$. high polyunsaturated as opposed to EFA-deficient diet $v$. different levels of polyunsaturated fat) differed, as also did the type of assay. In fact, in one study the content of EFA has been found to be critical (Erickson et al. 1983). Cytotoxicity was found to be significantly higher in peritoneal exudate cells from rats fed on $5 \mathrm{~g}$ $\mathrm{EFA} / \mathrm{kg}$ compared with those fed on an EFA-deficient diet, but increasing the content of polyunsaturated fatty acids further to 80 or $200 \mathrm{~g} / \mathrm{kg}$ reduced the cytotoxic activity. The possibility of a bell-shaped relation between EFA content of the diet and immune function is an important consideration.

Studies of humoral immunity include those that find it to be depressed in mice (DeWille et al. 1979) or enhanced in rats (Biossoneault \& Johnston, 1983) by EFA deficiency. The latter authors suggest that not only the species difference but even the route of injection could be a factor in explaining this discrepancy. In another study (Friend et al. 1980), humoral immunity was depressed in guinea-pigs fed on a high-polyunsaturated-fat diet compared with those fed on a highly saturated, EFA-adequate diet, a result supported by another study using mice (Erickson $e t$ al. 1983).

To summarize these diet studies, therefore, one may say that many apparent contradictions between one study and another may be due to too superficial an analysis of the results obtained. Not only the type but the quantity of fat used is important. A diet containing high levels of polyunsaturated fatty acids may give quite different results from one which has a low but adequate level of EFA, whilst a diet high in saturated fat but adequate in EFA needs to be distinguished from one totally deficient in EFA. Similar arguments apply to the type of assay used. Although two assays may purport to measure the same response, the point at which lipid modification acts may be such that apparently contradictory results 
may be obtained from two sets of experiments. For example, modification of the lipid composition of cell membranes could be directly affecting indices in the end assay in a different manner between two experiments, thus confusing the effect on the overall immune response. Precision is essential in defining not only the conditions used but also the effect observed.

\section{Effects on auto-immune disease and inflammation in mice and rats}

One of the most striking demonstrations of the effect of dietary lipid on immune function derives from experiments with strains of mice that spontaneously develop auto-antibodies. It has been found that removal of fat from the diet of NZB/NZW $\mathrm{F}_{1}$ hybrid mice greatly prolongs their survival (Fernandes et al. 1973). Moreover, both the quantity of fat and its degree of unsaturation has been found to modify the production of IgM and IgC differentially (Levy et al. 1982; Levy \& Morrow, 1983). Diets enriched in polyunsaturated oil (evening primrose oil) have been shown to inhibit chronic adjuvant-induced polyarthritis in rats substantially (Kunkel et al. 1982).

\section{The role of prostaglandins}

Space does not permit a full review of the effect of prostaglandins on the immune response. An extensive recent review is available (Goodwin \& Ceuppens, 1983). Much attention has, however, been directed to the possibility that the effect of dietary lipid modification could be mediated through influences on the formation of prostaglandins. $\mathrm{PGE}_{2}$ is the prostaglandin found to be most active in regulating the immune response, and generally has been found to act as a negative feedback inhibitor of T-cell responses. However, in some instances activation has been observed.

The possibility that a bell-shaped curve may exist also in the relation between prostaglandin concentration and immune function has been suggested (Mertin

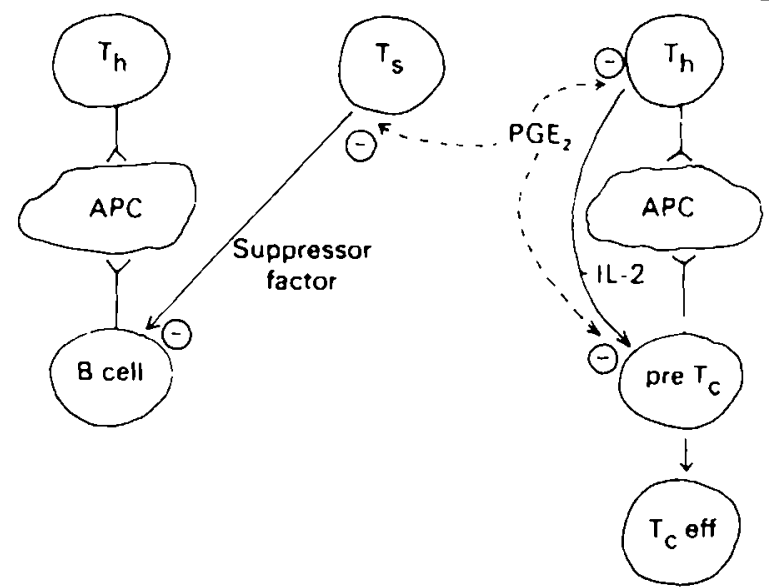

Fig. 2. Points at which prostaglandin $E_{2}$ may act in regulation of the immune response. The $T$ cells comprise subsets of helper cells $\left(T_{h}\right)$, suppressor cells $\left(T_{g}\right)$, precursors of effector $T$ cells (Pre $T_{c}$ ) or effector $T$ cells $\left(T_{c}\right.$ eff). For the initiation of immune response, antigen $\left(X\right.$ or $\left.X^{\prime}\right)$ is presented to helper cells by an antigen-presenting cell (APC). 
et al. 1984). As indicated in Fig. 2, PGE 2 may act by decreasing IL-2 production, but also has been shown to inhibit the response of T-cells to IL-2 (Goodwin \& Ceuppens, 1983). With regard to the humoral immune response, $\mathrm{PGE}_{2}$ may enhance immunoglobulin production and appears to inhibit T-cell suppression of B-cell function (Lydyard et al. 1982; Staite \& Panayi, I982; Goodwin \& Ceuppens, 1983). A useful recent review of prostaglandin regulation of B-cell function is available (Staite \& Panayi, I984).

In the past, the majority of studies have been concerned with the effect on immunocompetence of dietary modification of fatty acids of the n-6 series, especially linoleic acid which is contained in high amounts in maize, safflower, or sunflower oils or evening primrose oil (which also contains about $80 \mathrm{mg} \gamma$-linolenic $\mathrm{acid} / \mathrm{g}$ ). Dietary enrichment with such oils elevates the level of linoleic acid in animal tissue phosphoglycerides (including lymphocytes; Tsang et al. 1980) and usually tends if anything to elevate arachidonic acid levels also (Stubbs \& Smith, 1984). In contrast, feeding oils rich in fatty acids of the n-3 series, such as linseed oil or fish oils, lowers the level of arachidonic acid in phosphoglycerides of tissue membranes, including those of lymphocytes (Marshall \& Johnston, 1983; Conroy et al. 1985). This would be expected to reduce prostaglandin production, not only by reducing the availability of substrate, but also because activation of phospholipases will release n-3 polyunsaturated fatty acids, which will compete with arachidonic acid for cyclo-oxygenase to reduce the level of 2-series prostaglandins or even to lead to the formation of 3 -series prostaglandins with altered biological activity. Feeding linseed oil has indeed been shown to reduce prostaglandin production by the spleen (Marshall \& Johnston, 1983) and peritoneal macrophages (Magrum \& Johnston, 1983). Thus, if dietary treatment is exerting an effect by modulating the production of prostaglandins, it might be expected that dietary enrichment with oils containing $n-3$ fatty acids would have opposite effects to treatment with oils containing $n-6$ fatty acids. One report has indicated that dosing with $n-3$ fatty acids or oils containing these acids exerts a similar effect to dosage with ethyl linoleate, suggesting that possibly the effect observed was not mediated through an action on prostaglandin production (Sanders et al. 1985).

\section{In vitro studies}

After the initial observation that inclusion of polyunsaturated fatty acids in in vitro incubations brought about inhibition in several lymphocyte function tests (Mertin et al. 1974) others have confirmed that fatty acids inhibit mitogen stimulation of $\mathrm{T}$ cells (see Mertin, 1982) and cytotoxicity (Gill \& Clark, 1980).

The possibility of artefactual effects must be borne in mind when free fatty acids are used, especially when they are dissolved in ethanol. It has been shown, for example, that unsaturated fatty acids (but not saturated acids) cause accumulation of diacylglycerols in lymphocytes (Homa et al. 1983). This can be avoided by adding the fatty acids as complexes with albumin, which prevents the accumulation of diacylglycerol, whilst inhibition of transformation still occurs (Weyman et al. 1977). Even in the presence of albumin, however, lipid droplets 
form in the cells (Stubbs et al. 1980). In contrast, low levels of arachidonic acid, even when added in ethanol solution, are stimulatory (Kelly \& Parker, 1979).

Mixtures of saturated and unsaturated fatty acids are much less inhibitory than saturated or unsaturated fatty acids alone, whilst a mixture of palmitate and oleate is particularly favourable (Tsang et al. 1977; Spieker-Polet \& Polet, 1981) for rat lymphocytes. The favourable effect of mixing saturated and unsaturated fatty acids led to the suggestion that the action of the fatty acids could be mediated through effects on membrane fluidity. However, experiments to test this hypothesis revealed that, if lipid droplets were removed (these gave artefactual decreases of polarization of the fluorescent probe used), purified membranes prepared from cells that had been incubated with linoleic acid were indistinguishable from those incubated with palmitate on the basis of fluorescence polarization measurements. Other workers also found, using lymphocytes incubated with various fatty acids (Poon \& Clark, 1982) and examining the membrane physical properties by electron spin resonance techniques, that no simple relation could be deduced between the degree of membrane fatty acid unsaturation and the physical properties. This has been discussed more extensively by Stubbs \& Smith (1984). More recently, we have found during feeding experiments with fish oil (D. M. Conroy, C. D. Stubbs, J. Belin and A. D. Smith, unpublished results) that purified thymocyte membranes from fish-oil- or olive-oil-fed rats were indistinguishable on the basis of fluorescence polarization measurements, despite appreciable incorporation of the long-chain highly-polyunsaturated n-3 fatty acids. Even when liposomes were prepared from liver microsomal phosphatidylethanolamine which had incorporated large amounts of these acids, the fluorescence polarization measurements were identical to similar liposomes from olive-oil-fed rats. However, the fluorescence anisotropy of the probe embedded in liposomes of two samples of egg-yolk phosphatidylethanolamine was significantly higher than was found for the liposomes of microsomal phosphatidylethanolamine from either group of rats. The most noticeable difference between the egg-yolk and the microsomal phosphatidylethanolamine is that if one sums the total $\mathrm{C}_{20}$ and $\mathrm{C}_{22}$ fatty acids, and also sums the $\mathrm{C}_{18}$ fatty acids, the egg-yolk phosphatidylethanolamine contains

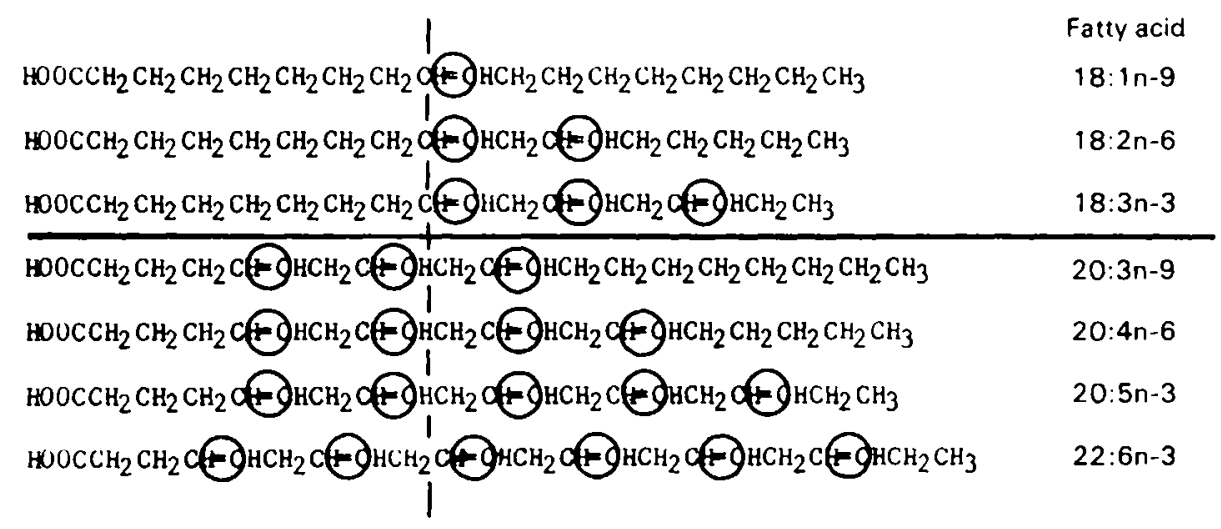

Fig. 3. Structures of $\mathrm{C}_{18}-\mathrm{C}_{22}$ fatty acids. 
appreciably more $(32 \%)$ of the $\mathrm{C}_{18}$ fatty acids than the microsomal phosphatidylethanolamine ( $9 \%$ for fish-oil-fed and $15 \%$ for olive-oil-fed rats), whereas the $\mathrm{C}_{20}$ and $\mathrm{C}_{22}$ fatty acids comprise less of the total (23\% egg yolk, $48 \%$ fish-oil-fed rats, $43 \%$ olive-oil-fed rats). An interesting feature of the fatty acids with twenty or more $\mathrm{C}$ atoms is the presence of double bonds in the region between $\mathrm{C}-\mathrm{I}$ and $\mathrm{C}-9$, in contrast to the $\mathrm{C}_{18}$ fatty acids which lack double bonds in this region (Fig. 3). In the bilayer, therefore, the fatty acids with twenty or more $\mathrm{C}$ atoms can be expected to introduce a diordering effect in the region near the headgroup which will not be the case for saturated fatty acids (which induce a high degree of order in this region, see Seelig \& Waespe-Sarcevic (1978)) or $\mathrm{C}_{18}$ unsaturated fatty acids. Whether or not this is the reason for the difference in fluorescence anisotropy between the phosphatidylethanolamines from the egg yolk and the microsomes remains to be seen, but it is a point that could repay examination. A corollary would be that replacements within the $\mathrm{C}_{18}$ group of acids could be achieved with minimal disturbance of physical properties. In biological systems it is often observed that replacements occur within, rather than across these groups.

\section{Conclusion}

In this review we have been concerned especially with the effects of changes in the degree of unsaturation of membrane lipid fatty acyl groups on immune function but we have indicated that dietary lipid modification may exert effects on the immune response through changes in cholesterol levels, or in plasma lipoproteins. It is clear that the immune response is subject to the influence of dietary lipid, and the effects on auto-immune disease in mice and in experimental inflammation are particularly striking. However, much remains to be learned concerning the mechanisms by which these influences are brought about.

\section{REFERENCES}

Biossoneault, G. A. \& Johnston, P. V. (1983). Fournal of Nutrition I 13, I $187-1194$.

Broitman, S. A., Vitale, J. J., Vavrousek-Jakuba, E. \& Gottlieb, L. S. (1977). Cancer 40 (Suppl.), $2455^{-24} 6_{3}$.

Carlomagna, M. A., O'Brien, B. C. \& McMurray, D. N. (1983). Fournal of Nutrition Ir3, $610-6 \mathrm{r} 7$.

Carroll, K. K. \& Khor, H. T. (1975). Progress in Biochemistry and Pharmacology 10, 308-353.

Clifford, C. K., Smith, L. M., Erickson, K. L., Hamblin, C. L., Creveling, R. K. \& Clifford, A. J. (1983). Fournal of Nutrition $113,669-679$.

Cuthbert, J. A. \& Lipsky, P. E. (1983). Fournal of Lipid Research 24, $1512-1524$.

DeWille, J. W., Fraker, P. J. \& Romsos, D. R. (1979). Fournal of Nutrition I09, $1018-1027$.

DeWille, J. W., Fraker, P. J. \& Romsos, D. R. (1981). Fournal of Nutrition $111,2039-2043$.

DiLuzio, N. R. (1972). Advances in Lipid Research $\mathrm{r0,43-88.}$

Erickson, K. L., Adams, D. A. \& McNeill, C. J. (1983). Lipids 18, 468-474.

Fernandes, G., Yunis, E. J., Jose, D. G. \& Good, R. A. (1973). International Archives of Allergy and Applied Immunology 4, 770-782.

Fontana, A., Fierz, W. \& Wekerle, H. (1984). Nature 307, 273-276.

Friend, J. V., Lock, S. O., Gurr, M. I. \& Parish, W. E. (1980). International Archives of Allergy and Applied Immunology 62, 292-301.

Gill, R. \& Clark, W. (1980). Fournal of Immunology 125, 689-695. 
Goodwin, J. S. \& Ceuppens, J. (1983). Fournal of Clinical Immunology 3, 295-315.

Homa, S. T., Conroy, D. M. \& Smith, A. D. (1983). Biochimica et Biophysica Acta 752, 315-323.

Kelly, J. P. \& Parker, C. W. (1979). Fournal of Immunology 122, I 556-1 562.

Kollmorgen, G. M., Sansing, W. A., Lehman, A. A., Fisher, G., Longley, R. E., Alexander, S. S., King, M. M. \& McCay, P. B. (1979). Cancer Research 39, 3458-3462.

Kunkel, S. L., Ogawa, H., Ward, P. A. \& Zurier, R. B. (1982). Progress in Lipid Research 20, $885-888$.

Levy, J. A., Ibrahim, A. B., Shirai, T., Ohta, K., Nagasawa, R., Yoshida, H., Estes, J. \& Gardner, M. (1982). Proceedings of the National Academy of Sciences, USA 79, 1974-1978.

Levy, J. A. \& Morrow, W. J. W. (1983). Immunology Today 4, 249-250.

Locniskar, M., Nauss, K. M. \& Newberne, P. M. (1983). Yournal of Nutrition 113, $95^{1-961 .}$

Loria, R. M., Kibrick, S. \& Madge, G. E. (1 976). Fournal of Infectious Diseases 1 33, 655-662.

Lydyard, P. M., Brostoff, J., Hudspith, B. N. \& Parry, H. (1982). Immunology Letters 4, 1 13-1 16.

Magrum, L. J. \& Johnston, P. V. (1983). Lipids 18, 514-521.

Mandel, G. \& Clark, W. R. (1978). Journal of Immunology 120, 1637-1643.

Marshall, L. A. \& Johnston, P. V. (1983). Lipids 18, 737-742.

Mertin, J. (1976). Transplantation 21, $1-4$.

Mertin, J. (1982). Progess in Lipid Research 20, $85 \mathrm{I}-856$.

Mertin, J., Hughes, D., Shenton, B. K. \& Dickinson, J. P. (х974). Klinishe Wochenschrift 52, $24^{8-250 .}$

Mertin, J. \& Hunt, R. (1976). Proceedings of the National Academy of Sciences, USA 73, $928-931$.

Mertin, J., Meade, C. J., Hunt, R. \& Sheena, J. (1977). International Archives of Allergy and Applied Immunology 53, 469-473.

Mertin, J., Stackpoole, A. \& Shumway, S. J. (1984). Transplantation 37, 396-402.

Morse, J. J., Witte, L. D. \& Goodman, D. S. (1977). Fournal of Experimental Medicine 146, $1791-1798$.

Nutter, R. L., Gridley, D. S., Kettering, J. D., Drexler, D. L. \& Slater, J. M. (I982). Cancer Letters $17, \mathrm{I}^{-18} \mathrm{~S}_{5}$.

Papamichail, M., Tsokos, G., Pepys, M. B., Weyman, C., Belin, J. \& Smith, A. D. (1979). Immunology 38, 1 $17-122$.

Poon, R. \& Clark, W. R. (1982). Biochimica et Biophysica Acta 689, $230-240$.

Sanders, T. A. B., Grahame, M. \& Mistry, M. (1985). Proceedings of the Nutrition Society 44, 6A.

Santiago-Delpin, E. A., Roman-Franco, A. A. \& Colon, J. I. (1982). Lipids 17, 727-732.

Santiago-Delpin, E. A. \& Szepsenwol, J. (1977). Fournal of the National Cancer Institute 59, 459-46r.

Seelig, J. \& Waespe-Sarcevic, N. (1978). Biochemistry 17, 3310-3315.

Simpson, E. \& Chandler, P. (1981). Immunology Today 2, 237-238.

Spieker-Polet, H. \& Polet, H. (1981). Fournal of Immunology 126, 949-954.

Staite, N. D. \& Panayi, G. S. (1982). Clinical and Experimental Immunology 49, 11 5-122.

Staite, N. D. \& Panayi, G. S. (1984). Immunology Today 5, 1 75-1 78.

Stubbs, C. D. \& Smith, A. D. (1984). Biochimica et Biophysica Acta 779, 89-137.

Stubbs, C. D., Tsang, W. M., Belin, J., Smith, A. D. \& Johnston, S. M. (1980). Biochemistry I9, $275^{6}-27^{62}$.

Traill, K. N. \& Wick, G. (1984). Immunology Today $3,70-76$.

Tsang, W. M., Belin, J. \& Smith, A. D. (1980). British fournal of Nutrition 43, 367-373.

Tsang, W. M., Weyman, C. \& Smith, A. D. (1977). Biochemical Society Transactions 5, 153-1 54.

Weyman, C., Morgan, S. J., Belin, J. \& Smith, A. D. (1977). Biochimica et Biophysica Acta 496, $155^{-166 .}$ 